\begin{tabular}{|l|l|l|}
\hline \multicolumn{2}{|c|}{ PublisherInfo } \\
\hline \hline PublisherName & $:$ & BioMed Central \\
\hline \hline PublisherLocation & $:$ & London \\
\hline \hline PublisherImprintName & $:$ & BioMed Central \\
\hline \hline
\end{tabular}

\title{
IL-10 reduces arthritis and adenovirus-mediated inflammation
}

\begin{tabular}{|c|c|c|}
\hline \multicolumn{3}{|c|}{ ArticleInfo } \\
\hline ArticleID & : & 72 \\
\hline ArticleDOI & : & 10.1186/ar-2001-70103 \\
\hline ArticleCitationID & : & 70103 \\
\hline ArticleSequenceNumber & : & 29 \\
\hline ArticleCategory & : & Paper Report \\
\hline ArticleFirstPage & : & 1 \\
\hline ArticleLastPage & : & 3 \\
\hline ArticleHistory & : & $\begin{array}{ll}\text { RegistrationDate } & : 2001-7-31 \\
\text { Received } & : 2001-7-3 \\
\text { OnlineDate } & : 2001-7-31\end{array}$ \\
\hline ArticleCopyright & : & Biomed Central Ltd2001 \\
\hline ArticleGrants & 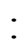 & \\
\hline ArticleContext & : & 130753311 \\
\hline
\end{tabular}




\section{Keywords}

Adenovirus-mediated gene therapy, CIA, IL-10, inflammation

\section{Context}

Interleukin (IL)-10 is a regulatory cytokine that has been shown to have both immunostimulatory and immunosuppressive properties. It has also been shown to be effective in the symptomatic treatment of some inflammatory conditions. Several studies have demonstrated that IL-10 plays a key immunoregulatory role in rheumatoid arthritis (RA). This study uses a collagen-induced arthritis (CIA) model of RA to investigate whether prolonged, systemic administration of homologous murine IL-10 using adenoviral gene delivery is effective in treating established arthritis. Furthermore, given that intravenous delivery of adenoviral vectors is known to cause inflammation in the liver, the question of whether IL-10 gene delivery can suppress adenovirus-induced hepatic inflammation is addressed.

\section{Significant findings}

Adenovirus-delivered IL-10 (AdIL-10) effectively controlled the progression of articular inflammation, while empty vector had no effect. AdIL-10 administration reduced both in vitro lymphocyte proliferation and interferon-a production, but had no effect on levels of antibodies to type II collagen. Systemic adenovirus administration did induce a mild hepatic inflammation, as judged by morphological analysis of the liver, assessment of overall inflammation and, more specifically, portal and parenchymal inflammation, apoptosis and mitoses. This mild hepatic inflammation was overcome by AdIL-10 treatment in two out of three animals. Significant hepatic inflammation was only observed following injection of adenovirus at levels 100-fold higher than the effective therapeutic dose. AdIL-10 treatment also attenuated the delayed-type hypersensitivity (DTH) response to high doses of adenovirus; however, this immunosuppressive effect occurred only if AdIL-10 was administered before sensitization, rather than between sensitization and challenge, indicating that IL-10 blocks the initial priming of $\mathrm{T}$ cells.

\section{Comments}


Although the potential use of adenovirus gene delivery systems in human therapy remains questionable, this study is of particular importance to this field; not only does it show that adenoviral administration of homologous murine IL-10 is effective in treating established CIA, but it also addresses some of the generic problems associated with the use of adenovirus gene delivery systems. IL-10 is shown to reduce the cellular immune responses to adenoviral antigens administered intravenously, and in particular to reduce hepatic inflammation. IL-10 has therapeutic potential, therefore, not only in the treatment of inflammatory diseases, but also for use in conjunction with adenovirus-mediated gene therapy. Additional experiments, however, need to be carried out to establish the effect of AdIL-10 treatment on bone and cartilage destruction. Furthermore, although remaining therapeutically effective, serum IL-10 levels declined at 21 days post-injection; therefore, the requirement for further AdIL-10 treatment in the longer term, and the effect this may have on cellular immune responses, now require investigation.

\section{Methods}

Recombinant adenovirus construction, CIA, model, cell proliferation assays, DTH reactions, histological analysis

\section{Additional information}

\section{References}

1. Quattrocchi E, Dallman MJ, Dhillon AP, Quaglia A, Bagnato G, Feldmann M: Murine IL-10 gene transfer inhibits established collagen-induced arthritis and reduces adenovirus-mediated inflammatory responses in mouse liver. J Immunol. 2001, 166: 5970-5678.

This PDF file was created after publication. 